\title{
Effect of Dexamethasone Iontophoresis on Acute Bell's Palsy Patients
}

\author{
MOHAMED N. EL-BAHRAWY, Ph.D.*; HANAN H. ABD EL-ALEEM, M.D.**; \\ WALEED T. MANSOUR, Ph.D.* and MOHAMMED R. IBRAHIM, M.Sc.* \\ The Departments of Physical Therapy for Neuromuscular \& Neurosurgical Disorders \& its Surgery, \\ Faculty of Physical Therapy* and Department of Neurology, Faculty of Medicine**, Cairo University, Egypt
}

\begin{abstract}
Background: Bell's palsy is an idiopathic lower motor neurone palsy of the facial nerve. It is the most common cause of rapid-onset unilateral facial weakness. It often manifests rapidly.

Aim of the Study: This study aimed to evaluate the effect of Dexamethasone iontophoresis on acute Bell's palsy.

Subject and Methods: Thirty patients from both sexes, diagnosed as acute Bell's palsy were included in this study recruited from Neurology Outpatient Clinic of Faculty of Physical Therapy, Cairo University from July 2014 to October 2015. They were assigned into two equal groups a control group (A) and study group (B). GA received oral systemic steroids and aplacebo effect of iontophoresisWhile GB received the same oral drugs and Dexamethasone Iontophoresis. The patients were assessed with Electrical Response Grading as objective method for assessment and the Yanagihara Grading Scale (YGS) as clinical method for evaluation pre and post the iontophoresis.
\end{abstract}

Results: Post physiotherapeutic evaluation revealed significant difference between group A and group B regarding (ERG) and (YGS) 0.001 .

Conclusion: Dexamethasone iontophorsis is effective in treatment of acute Bell's palsy.

Key Words: Bell's palsy-Dexamethasone-Iontophoresis.

\section{Introduction}

BELL'S palsy is a disorder in which a nerve that controls the facial muscles becomes dysfunctional, resulting in weakness or paralysis of one side, or more rarely, both sides of the face [1]

Bell's palsy, named after the scottish anatomist, Sir Charles Bell, is the most common acute mononeuropathy, or disorder affecting a single nerve,

Correspondence to: Dr. Mohamed N. El-Bahrawy,

The Department of Physical Therapy for Neuromuscular \& Neurosurgical Disorders \& its Surgery, Faculty of Physical Therapy, Cairo University, Egypt and is the most common diagnosis associated with facial nerve weakness/paralysis [2].

The incidence rate of this disease ranges from 20 to 25 cases per 100,000 populations annually. Women and men are usually equally affected. It occurs with equal frequency on the right and left side of the face [3]

The etiology of Bell's palsy is unknown but viral infection, vascular ischemia, and autoimmune disease has been postulated as the possible pathomechanisms [4].

The precise cause of Bell's palsy is unknown. A theory suggests that swelling of the facial nerve trunk in the narrow confines of the facial canal leads to local ischemia, which in turn leads to further swelling and edema consequently the result is local interruption of blood supply to the facial nerve and thus extension of the ischemic injury. It has been seen in Magnetic Resonance Imaging (MRI) scans [5].

The clinical picture may differ, depending on the location of the lesion of the facial nerve along its course from stylomastoid foramen to the muscles. Also, symptoms and signs may differ as the facial nerve carries not only motor fibers including fibers to the stapedius muscle but also supplies autonomic innervation of the lacrimal gland, submandibular gland, sensation to part of the ear, and taste to the anterior two thirds of the tongue via chorda tympani [6]

Bell's palsy is diagnosed upon abrupt onset of impaired facial expression due to unilateral facial weakness of all facial nerve branches leading to dry eye, saliva runs out of the mouth, the inability to close or wink the eye or close the mouth, dropping of the brow or the corner of the mouth, in 
addition to numbness or pain around the ear, mastoid, or angle of the mandible, an altered sense of taste, hypersensitivity to sounds [3-7]

Patients may also mention otalgia, aural fullness, or mild retroauricular pain, which may even precede the palsy [4].

Speech and eating may also be disturbed. Severe pain suggests herpes simplex or zoster infection and may precede vesicular eruption and progression to Ramsay Hunt syndrome, which is characterized by typical cutaneous vesicles and vesicles in the conchal bowl, soft palate, or tongue and by vestibulo-cochlear dysfunction [6].

\section{Material and Methods}

This study was carried out on thirty patients suffering from acute one sided bell's palsy not more than one week duration from onset with normal and stable vital signs that, examined by a neurologist. Subjects from both gender. Their ages ranged from 20 to 40 years were randomly assigned into two equal groups. All subjects signed a written informed consent form.

\section{Instrumentation for evaluation:}

I- NEUROMED 4080 Device Fig. (1) (CARCI) production by using the electrical response grading of the facial muscles before and after the treatment course.

The patients positioned sitting on a back chair. The skin prepared as clean as possible by alcohol, then the following steps were followed:

\section{A- Electrical response grading:}

- The electrodes were moistened by Gel.

- The electrodes were positioned on face on motor points of each muscle of (frontalis, orbicularis oculi and orbicularis oris) Figs. $(2,3)$.

- Low frequency, disperse-dense wave, was applied at a transition frequency of $1 \mathrm{~Hz}$ (disperse wave) and $100 \mathrm{~Hz}$ (dense wave).

- The response of facial muscles was observed after applying low frequency, disperse-dense wave, at a transition frequency of $1 \mathrm{~Hz}$ (disperse wave) and $100 \mathrm{~Hz}$ (dense wave) and its degrees were labeled according to its response as follow:

1-Excellent: At the intensity of $4 \mathrm{~mA}$, facial muscle twitching was observed at disperse wave; observed contraction of facial muscle reached or exceeded normal contraction at dense wave.

2- Moderate: Output intensity was between 4 and $6 \mathrm{~mA}$; muscle twitching appeared at disperse wave; slight contraction was visible at dense wave, but did not reach the normal contraction.

3- Poor: Output intensity was $>6 \mathrm{~mA}$; slight muscle twitching was observed at disperse wave; no contraction was seen at dense wave.

4- No response: Output intensity was $>6 \mathrm{~mA}$; no muscle contraction [8].

II- The Yanagihara Grading Scale (YGS) is the standard method used in the Japanese literature. It is obtained by the subjective assessment of total symmetry at rest and nine different facial movements using a three steps grading (0-24) which when summated give a scale from 0 (total paralysis) to 40 (normal) [9]. On this scale, 0 indicated total palsy, 2 indicated partial palsy, and 4 indicated normal function.

For evaluation the following steps were followwed:

B- Yanagihara Grading Scale:

- Patients were positioned as sitting on a back chair.

- The affected side was observed at rest and at each expressive state of the scale.

- The subjects were asked to perform each facial movement with the affected side of the following (wrinkle forehead, close eye normally, close eye forcefully, close eye only on involved side, wrinkle nose, blow out cheeks, whistle, grin, depress lower lip) and it was compared with the sound side.

- The score was obtained according to observation as:

- Normal: 4.

- Weak: 2.

- No motion: 0.

- The points given to each expressive state were added, and the total was called the paralysis score, which ranged from 40 (normal) to 0 (complete paralysis). The paralysis score was also expressed as a percentage (total points/40 X 100).

(0) Means total paralysis.

(40) Means normal.

(20) Means weak.

\section{Instrumentation for treatment:}

I- Activa Dose $\AA$ II Iontophoresis Delivery Unit Fig. (4) ActivaTek Inc. USA production Model C-ADIID. 


\section{Treatment protocol:}

After the baseline measurements, the patients were randomly assigned into two equal groups. The first group, control groop (GA) received oral systemic steroids prescribed by the physician plus the placebo effect of Dexamethasone iontophoresis as follow:

- Patients positioned sitting on a back chair.

- The skin was prepared as clean as possible by alcohol.

- The patient's jewellery were removed and the procedures were explained to the patients.

- The machine was checked in good working order.

- The electrodes were moistened with aqueous normal saline solution.

The electrodes were positioned on face as (the negative pole on the main nerve trunk at the stylomastoid foramen behind the ear on the affected side and the positive one was on the trapezius muscle for (20 minutes) application Fig. (5).

Group B (study group) received the same program of group A but with Dexamethasone iontophoresis instead of its placebo effect with the same procedures as GA but with Dexamethasone with the following parameters $0.5 \mathrm{~mA} / \mathrm{cm}^{2}$ was applied at the negative (cathode), a current of $2 \mathrm{~mA}$ was delivered using an electrode of $6 \mathrm{~cm}^{2}, 4 \mathrm{mg} / \mathrm{mL}$ aqueous solution of dexamethasone at the NEGATIVE pole, for 20 minutes [10]. The iontophoresis was applied for two weeks period [11].

\section{Statistical analysis:}

The data are described and presented as mean SD. Comparison of means using student $t$-test. The level of significance was at $p<0.05$.

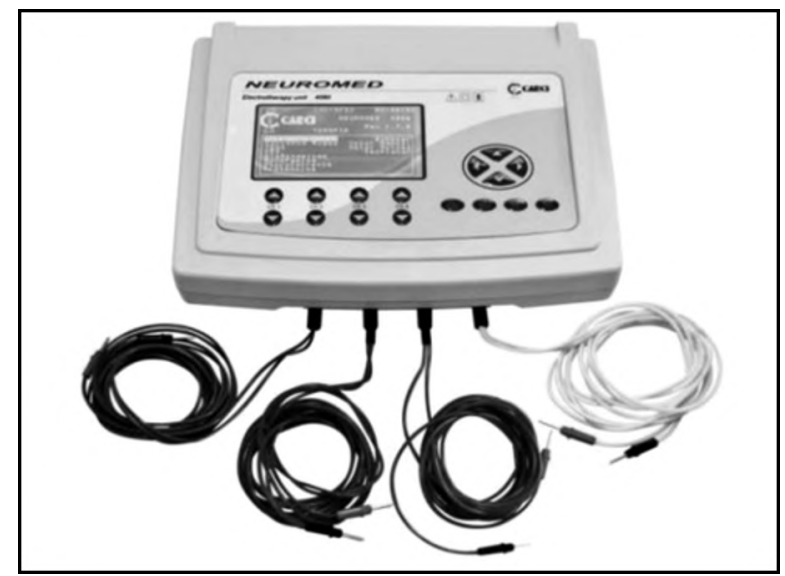

Fig. (1): NEUROMED 4080-CARCI-Brazil-2015. The evaluation, was performed before and after treatment.

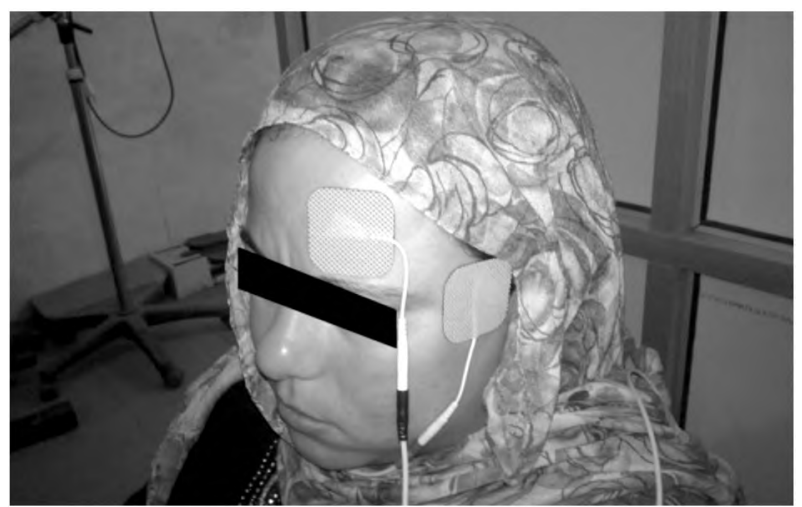

Fig. (2): Electrodes placement over frontalis and orbicularis oculi.

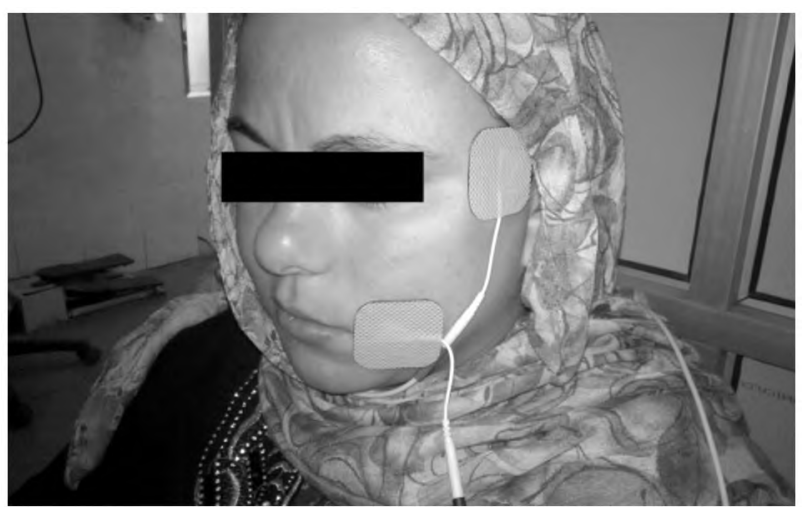

Fig. (3): Electrodes placement over orbicularis oculi and orbicularis oris.

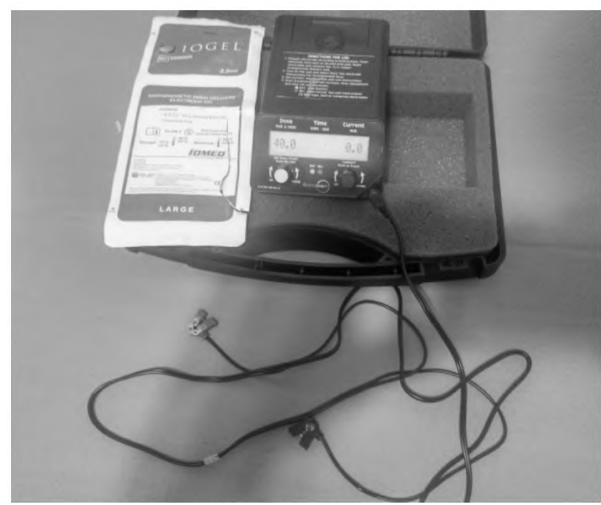

Fig. (4): ActivaDose® II Iontophoresis Delivery Unit.

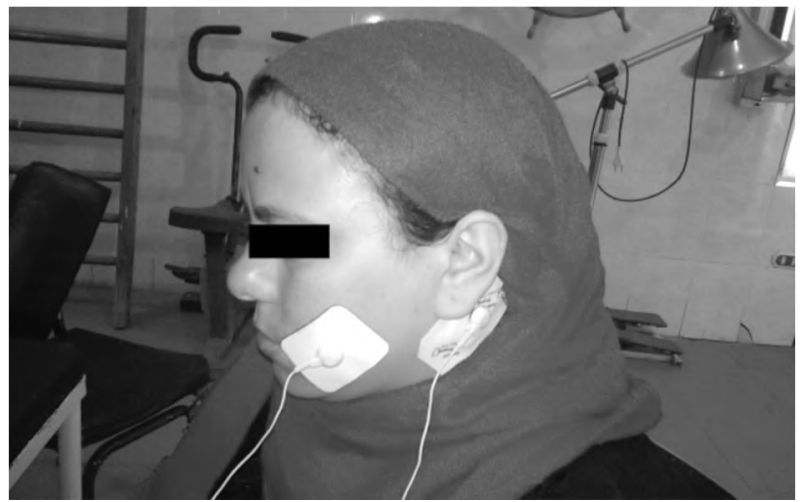

Fig. (5): Dexamethasone iontophoresis. 


\section{Results}

1- On comparison between before and after treatment as regarding Electrical Response Grading (ERG) and Yanagihara Grading Scale (YGS) in group (A) who was treated by placebo iontophoresis, the mean values of ERG were (7.1 \pm 1.7$),(6.9 \pm 1.8)$ respectively, $t=1.8 p>0.001$ and the mean values of Yanagihara Grading Scale (YGS) were $(31.1 \pm 17.6),(32.7 \pm 17.4)$ respectively $t=-1.9 p>0.001$ (Table 1 ), Fig. (6).

There was no statistically significant difference in the mean and standard deviation between before and after treatment program in group (A) regarding electrical response grading and yanagihara grading scale.

2- On comparison between before and after treatment as regarding Electrical Response Grading (ERG) and Yanagihara Grading Scale (YGS) in group (B) who was treated by dexamethasone iontophoresis, the mean values of (ERG) were (7.3 \pm 1.7$),(5.7 \pm 1.4)$ respectively, $t=6.3 p<0.001$ and the mean values of (YGS) were (38.3 \pm 16.7$)$, $(58.3 \pm 17.4)$ respectively, $t=-7.6 p<0.001$ (Table 2), Fig. (7).

There was statistically significant difference in the mean and standard deviation between before and after treatment program in group (B) regarding electrical response grading and yanagihara grading scale.

Table (1): Comparison between before and after ttt as regarding ERG and YGS in group (A).

\begin{tabular}{lllll}
\hline & Before & After & Test & $p$-value \\
\hline ERG: & & & & \\
$\quad$ Range & $4-10$ & $4-10$ & $t=1.8$ & 0.082 \\
$\quad$ Mean \pm SD & $7.1 \pm 1.7$ & $6.9 \pm 1.8$ & & \\
YGS: & & & & \\
$\quad$ Range & $15-65$ & $20-70$ & $t=-1.9$ & 0.063 \\
$\quad$ Mean \pm SD & $31.1 \pm 17.6$ & $32.7 \pm 17.4$ & & \\
\hline
\end{tabular}

Comparison between before and after treatment as regarding Electrical Response Grading (ERG) and Yanagihara Grading Scale (YGS) in group (A).

Table (3): Comparison between group A and group B as regarding ERG.

\begin{tabular}{lllll}
\hline & Group (A) & Group (B) & Test & $p$-value \\
\hline ERG before: & & & & \\
$\quad$ Range & $4-10$ & $4-10$ & $t=-0.32$ & 0.750 \\
$\quad$ Mean \pm SD & $7.1 \pm 1.7$ & $7.3 \pm 1.7$ & & \\
ERG after: & & & & \\
$\quad$ Range & $4-10$ & $4-8$ & $t=2.2$ & $0.040^{*}$ \\
$\quad$ Mean \pm SD & $6.9 \pm 1.8$ & $5.7 \pm 1.4$ & & \\
Difference: & & & & \\
$\quad$ Range & $0-1$ & $1-4$ & $t=-5.1$ & $0.001^{* *}$ \\
$\quad$ Mean \pm SD & $0.2 \pm 0.41$ & $1.6 \pm 0.98$ & & \\
\hline
\end{tabular}

Comparison between group (A) and group (B) as regarding (ERG) before and after treatment and difference.
3- On comparison between group (A) and group (B) as regarding (ERG) before and after treatment and difference, the mean values of group (A) were $(7.1 \pm 1.7)$ and $(6.9 \pm 1.8)$ respectively, while group (B) were $(7.3 \pm 1.7)$ and $(5.7 \pm 1.4)$ respectively, and the mean difference of group (A) was $(0.2 \pm 0.41)$, while the mean difference of group (B) was (1.6 \pm 0.98$)$ (Table 3), Fig. (8).

There was statistically significant difference in the mean and standard deviation in group (B) as regarding (ERG) before and after treatment, while there was statistically no significant difference in the mean and standard deviation in group (A) as regarding (ERG) before and after treatment.

4- On comparison between group (A) and group (B) as regarding (YGS) before and after treatment and the difference, the mean values of group (A) were (30.1 \pm 17.6$)$ and $(32.7 \pm 17.4)$ respectively, while group (B) were $(38.3 \pm 16.7)$ and $(58.3 \pm 17.4)$ and the mean difference of group (A) was $(3 \pm 3.1)$, while the mean difference of

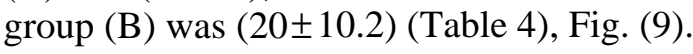

There was statistically significant difference in the mean and standard deviation in group (B) as regarding (YGS) before and after treatment, while there was statistically no significant difference in the mean and standard deviation in group (A) as regarding (YGS) before and after treatment.

Table (2): Comparison between before and after ttt as regarding ERG and YGS in group (B).

\begin{tabular}{lllll}
\hline & Before & After & Test & $p$-value \\
\hline$E R G:$ & & & & \\
$\quad$ Range & $4-10$ & $4-8$ & $t=6.3$ & 0.001 ** \\
$\quad$ Mean \pm SD & $7.3 \pm 1.7$ & $5.7 \pm 1.4$ & & \\
$\quad Y G S:$ & & & & \\
$\quad$ Range & $15-70$ & $35-85$ & $t=-7.6$ & $0.001 * *$ \\
$\quad$ Mean \pm SD & $38.3 \pm 16.7$ & $58.3 \pm 17.4$ & & \\
\hline
\end{tabular}

Comparison between before and after treatment as regarding Electrical Response Grading (ERG) and Yanagihara Grading Scale (YGS) in group (B).

Table (4): Comparison between group A and group B as regarding YGS and difference.

\begin{tabular}{|c|c|c|c|c|}
\hline & Group (A) & Group (B) & Test & $p$-value \\
\hline \multicolumn{5}{|l|}{ YSG before: } \\
\hline Range & $15-65$ & $15-70$ & $t=-1.4$ & 0.179 \\
\hline Mean \pm SD & $30.1 \pm 17.6$ & $38.3 \pm 16.7$ & & \\
\hline \multicolumn{5}{|l|}{ YSG after: } \\
\hline Range & $20-70$ & $35-85$ & $t=-4.04$ & $0.001 * *$ \\
\hline Mean \pm SD & $32.7 \pm 17.4$ & $58.3 \pm 17.4$ & & \\
\hline \multicolumn{5}{|l|}{ Difference: } \\
\hline Range & $0-10$ & $5-40$ & $t=-6.2$ & $0.001 * *$ \\
\hline Mean \pm SD & $3 \pm 3.1$ & $20 \pm 10.2$ & & \\
\hline
\end{tabular}
(YSG) before and after treatment and the difference. 


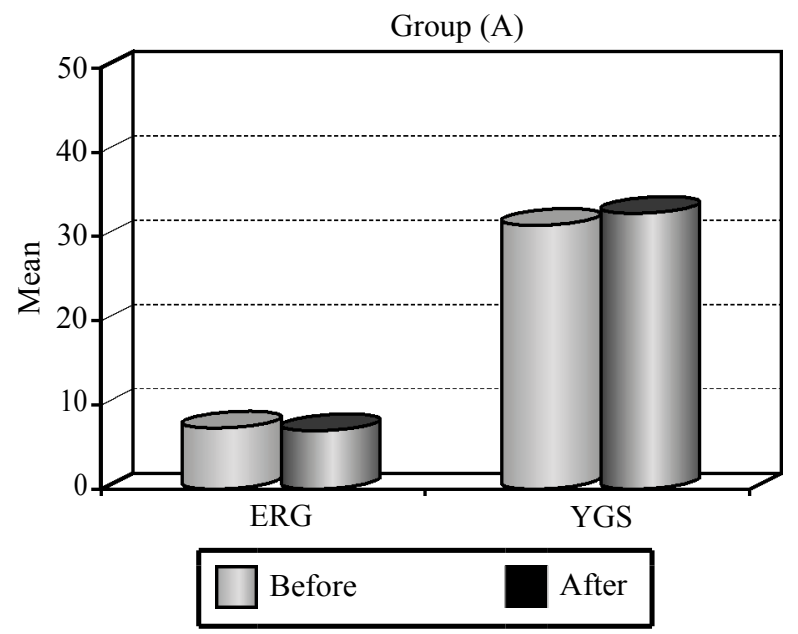

Fig. (6): Comparison between before and after ttt as regarding ERG and YGS in group (A).

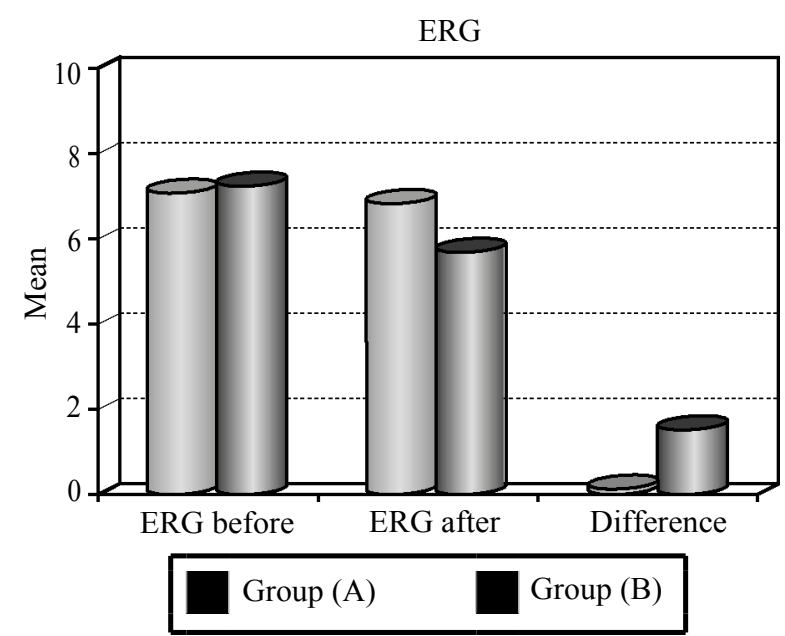

Fig. (8): Comparison between group A and group B as regarding ERG.

\section{Discussion}

This study was carried out to evaluate the effect of dexamethasone iontophoresis on acute bell's palsy.

Thirty patients ( 15 males and 15 females) aged from (20:40) years old participated in this study patients were selected from the out-patient clinic of Faculty of Physical Therapy, they were divided into two equal groups (group A and B) according to physical therapy intervention. The patients were assessed using Electrical Response Grading (ERG) and Yanagihara Grading Scale (YGS).

The variables measured were electrical response grading of muscles and nine facial expressions and at rest by YGS.

The results of this study demonstrated that, there was no statistically significant difference in

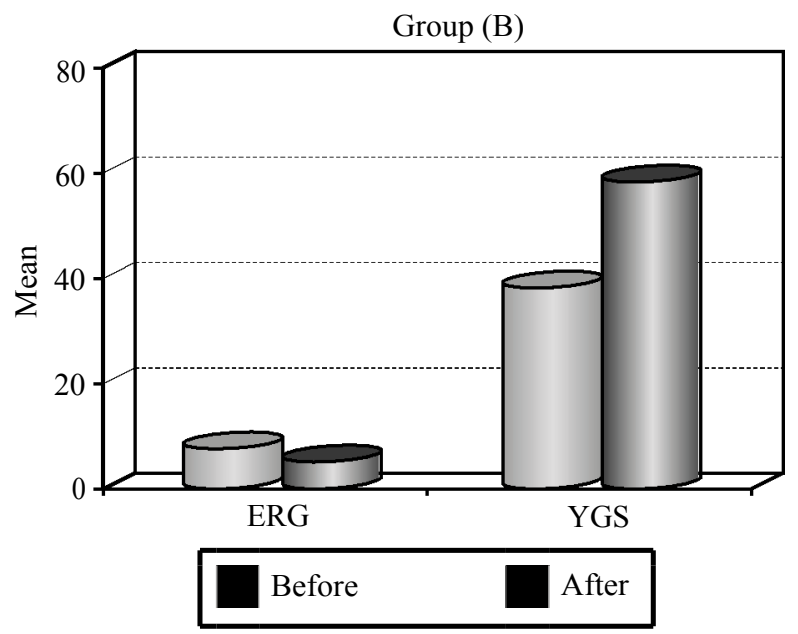

Fig. (7): Comparison between before and after ttt as regarding ERG and YGS in group (B).

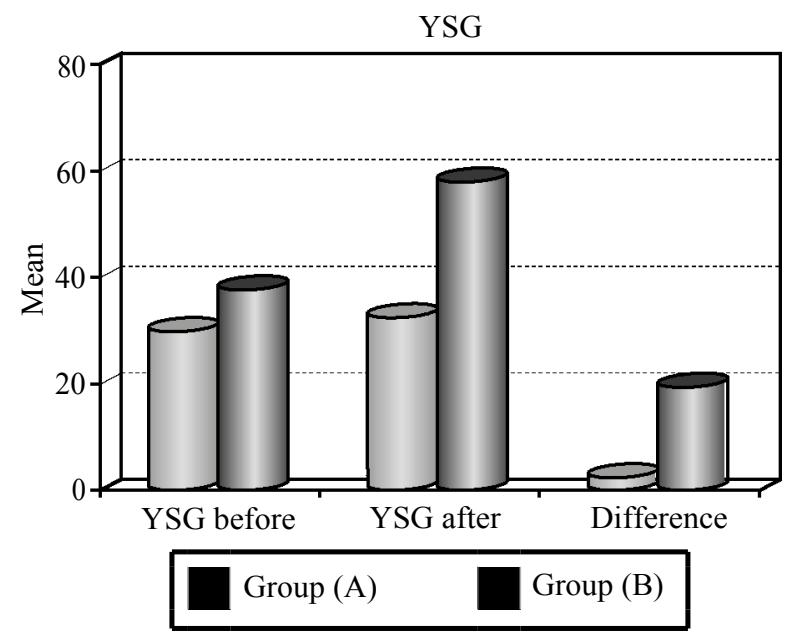

Fig. (9): Comparison between group A and group B as regarding YGS and difference.

the mean values of age, height, weight and sex between the patients in both groups. Additionally, there was no statistically significant difference in the mean values of affected sides between group A and group B before treatment. This indicates that the selection of patients in the both groups (group A and group B) was homogenous and this facilitated the comparison between them.

Regarding electrical response grading and yanagihara grading scale scores there were a statistically significant difference in the mean values of scores between group (A) and group (B) ( $p$ 0.001) after treatment, with the highest value in group B.

Although there are limited studies about the iontophoresis in treatment of acute Bell's palsy it has been shown to be in favor of dexamethasone iontophoresis in acute Bell's palsy that confirmed regarding the results of this study on comparing group (B) to group (A). 
Based on the finding of this study, group B that treated with Dexamethasone iontophoresis showed significantly greater gains than group $\mathrm{A}$ in both YGS and ERG. Therefore; this results suggested a rejection of the hypothesis which stated that there is no statistical significance in the effect of using Dexamethasone iontophoresis in acute Bell's palsy.

It appears that iontophoresis has many advantages of its use, that it is noninvasive, painless, sterile, and delivers medication through the skin through the use of an electric current's polarity [12]. Also, the results of this study were agreed with [13] Kimberly et al., who postulated that, Dexamethasone iontophoresis resulted in a statistically significant improvement of the facial nerve paresis involvement and motion in paresis postparotidectomy. So, it is effective and safe treatment modality.

Moreover these results agree with those achieved from [14] Gökolu et al., who stated that short term outcome indicated a relief in both clinical and objective measures in peripheral nerve lesions e.g. (carpal tunnel syndrome patients) who, were treated with dexamethasone iontophoresis.

Also, there is evidence to support that dexamethasone is the gold standard for iontophoresis application as it is an anti-inflammatory drug that can be used to treat various acute and chronic inflammatory conditions [1я Sankar et al.

Harris, [16] demonstrated that dexame-thasone is transferred iontopho-retically into all tissue layers underlying the electrode. He indicated that iontophoresis is an effective mode of delivering ionized anti-inflammatory drugs into inflamed tissues. It is effective painless and safe and provides viable alternative treatment. So, from all these we may conclude that dexamethasone may penetrate and reach a sufficient depth to the facial nerve to give the better improvement which are in agreement with our findings in the present study.

Another study was done by Banta, [17] support the results of the current study. AS Banta documented those steroids iontophoresis was successful in $58 \%$ of cases and concluded that iontophoresis might become an alternative to steroid injection to the carpal tunnel region.

Also the results of this study were consistent with the findings of Graham et al. [18], who found out that, pain at rest, on movement and on pressure, motion and enhancement of peripheral nerve regeneration after neuropathy were improved after using dexamethasone iontophoresis on animal models with peripheral nerve palsies.

The results of this study come in agreement with Panzade and Puranik, [19] who reported that the use of iontophoresis to facilitate underlying deep tissue penetration of drugs after topical application will be most beneficial in the treatment of local inflammatory conditions of nerves and muscles.

Also, the results of this study agree with Anders et al., [20] who stated that dexamethasone iontophoresis had improved functional recovery in nerve tissue. The possibility that, in-vivo dexamethasone iontophoresis can directly enhance the process of axonal regeneration is supported in-vitro studies. One of these studies showed that, dexamethasone iontophoresis can exert a direct effect on axons by guiding neuronal growth cones in-vitro and suggested that this action can be due to the interaction of steroids and direct current with some cytoplasmic protiens and particularly, to the enhancement of actin polyrization at the leading axon edge. Moreover there is evidence to support that iontophoresis may enhance recovery of neurons from injury by altering mitochondrial oxidative metabolism [20]

The simplest explanation for the effectiveness of iontophoresis as an stimulation of drug delivery was discussed by Allen, [21] who reported that when iontophoresis is performed, the active electrode (with the same charge as the drug) is placed over the tissues, which require medication. The indifferent or return electrode (with the opposite charge as the drug) containing a different electrolyte is placed at a convenient location elsewhere on the body. The electrodes are connected to the direct current source (iontophoresis device). The current is then gradually increased to the proper level for the time duration required.

The thermal mechanism was also one of the proposed methods by which Dexamethasone iontophoresis (direct current) affect the body systems Acar et al., [22] referred reduction of small rodents (mice, rats, rabbits) facial nerve amplitude to the thermal effect of direct current which increase the temperature of soft tissue surrounding the facial nerve. Increased temperature means more blood flow which may play a role in increasing nerve excitability as the blood is an electrical conductor. This also creates warm environment which enhance excitability.

On the other hand, there are some studies were done disagree with our results. A study was done by Aygul et al., [23] who compared between three 
different steroid treatment of CTS in acute stage fifty six hands of thirty one female patients were treated with local injection, iontophoresis and phonophoresis.

They stated that local injection is more effective than phonophoresis and iontophoresis which showed no significant improvement. In their study they wrapped the positive electrode with the absorbent pad that was sucked with a mixture of $0.1 \%$ dexamethasone while negative electrode on proximal arm, which completely different from our study as in their study, the time of the session was only (10min) while in our study is double time (20min), in their study the amount of steroids is small $0.1 \%$ only and is not sufficient while in our study is $0.4 \%$. In addition, they put the dexamethasone negative ion in the positive electrode which will attract the negative ion which makes penetration of the ions into the tunnel very difficult.

Julian et al., [24] stated that any improvement in the acute stage of nerve injury can be explained by spontaneous recovery which could occur due to nerve regeneration. Also, early beginning of treatment program would improve local circulation, resolution of local edema which decreased the compression and the ischemia of the nerve.

It can be concluded that the results of this study revealed significant improvement of group (B) in a form of a statistical significant difference in ERG and YGS scores post treatment, while there was no statistical significant difference in ERG and YGS scores post treatment in group (A).

\section{References}

1- BAUGH R.F., BASURA G.J., et al.: Clinical Practice Guideline: Bell's Palsy. Otolaryngology-Head and Neck Surgery, 149: S1, 2013.

2- PEITERSEN E.: Bell's palsy: The spontaneous course of 2,500 peripheral facial nerve palsies of different etiologies. Acta Otolaryngol. Suppl., (549): 4-30, 2002.

3- BASIC-KES V., et al.: "Peripheral facial weakness (Beel's plasy)“, Acta Clin. Croat., Vol. 52, No. 2, pp. 195-202, 2013.

4- FINSTERER J.: Management of peripheral facial nerve palsy. Eur. Arch. Otorhinol.-Aryngol., 265 (7): 743-52, 2008.

5- SEOK J.I., LEE D.K. and KIM K.J.: The usefulness of clinical findings in localising lesions in Bell's palsy: Comparison with MRI. J. Neurol. Neurosurg. Psychiatry, 79 (4): 418-20, 2008.

6- HOLLAND N.J. and WEINER G.M.: Recent developments in Bell's palsy. Br. Med. J., 329: 553-7, 2004.
7- ROOB G., FAZEKAS F. and HARTUNG H.P.: Peripheral facial palsy: Etiology, diagnosis and treatment. Eur. Neurol., 41: 3-9, 1999.

8- ZHOU Z.L., ZUO CONG, CHENG S.L., SHAO W.W and LIU L.P.: Application of grading evaluation on facial nerve function of Bell's palsy treated with electroacupuncture[J]. Zhongguo Zhen Jiu, 33 (8): 692-6, 2013.

9- KECSKES: Current Diagnostic, Pharmaceutic And Reconstructive surgical Methods In The Management of Facial Nerve Palsy, Szeged, 56 (4): 156-63, 2012.

10- BELANGER A.Y.: Therapeutic Electrophysical Agents: Evidence Behind Practice. ${ }^{2 n d}$ ed. Baltimore, MD: Wolters Kluwer/Lippincott Williams \& Wilkins, 251, 2010.

11- AMIRJANI N., ASHWORTH N.L., WATT M.J., et al.: Corticosteroid iontophoresis to treat carpal tunnel syndrome: A double-blind randomized controlled trial. Muscle Nerve, 39 (5): 627-633, 2009.

12- GRATIERI T., KALARIA D. and KALIA Y.N.: Noninvasive iontophoretic delivery of peptides and proteins across the skin. Expert Opin. Drug. Deliv., 8: 645-63, 2011.

13- KIMBERLY J. LEE, BS; WILLARD E. FEE, Jr., M.D. and DAVID J. TERRIS, M.D.: The Efficacy of Corticosteroids in Postparotidectomy Facial Nerve Paresis Laryngoscope, 112: November 2002.

14- GÖKOLU F., FINDIKOLU G., YORGANCIOLU Z., OKUMU M., CECELI E. and KOCAOLU S.: Evaluation of iontophoresis and Local Corticosteroid Injection in the Treatment of Carpal Tunnel Syndrome. Am. J. Phys. Med. Rehabil., 84 (2): 92-6, 2005.

15- SANKAR RAVI, Y. DASTAGIRI REDDY, N. VIJAYA BHASKAR, AUDI NARYANA, N. PRATHYUSHA and SOPHIA: A New Generation Approch Throug Transdermal Route Tech. Vol. 2, Issue [ISSN 0976-3783].

16- HARRIS W.D.: Topography of the facial nerve. Arch. Otolaryngol., 88: 264-7, 1982.

17- BANTA C.A.: A prospective, nonrandomized study of iontophoresis, wrist splinting, and anti-inflammatory medication in the treatment of early-mild carpal tunnel syndrome., Feb., 36 (2): 166-8, 1994.

18- GRAHAM W.P., PATAKY P.E., CALABRETTA A.M., MUNGER B.L. and BUDA M.J.: Enhancement of peripheral nerve regeneration with dexamethasone iontophoresis after neurorrhaphy. Surg. Forum, 24: 457-9, 1996.

19- PANZADE P., HEDA A., PURANIK P., PATNI M. and MOGAL V.: Enhanced transdermal delivery of granisetron by using iontophoresis, Spring, 11 (2): 503-12, 2012.

20- ANDERS J.J., GEUNA S. and ROCHKIND S.: Iontophoresis promotes regeneration and functional recovery of injured peripheral nerve. Neurol. Res., Mar., 26 (2): 233-9, 2004.

21- ALLEN Jr.: Iontophoretic transdermal delivery device. 03-26, 2003.

22- ACAR M., HULTGREN B., BOGGIO P.S., FREGNI F. and ZAGHI S.: Noninvasive facial nerve stimulation with 
direct electrical currents: Putative mechanisms of action for direct and alternating current stimulation. 2010 Jun., 16 (3): 285-307. doi: 10.1177/1073858409336227. Epub 2009 Dec. 29.

23- AYGÜL R., ULVI H., KARATAY S., DENIZ O. and VAROGLU A.O.: Determination of sensitive electrophys- iologic parameters at follow-up of different steroid treatments of carpal tunnel syndrome, Jun., 22 (3): 222-30, 2005.

24- JULIAN G.G., HOFFMANN J.F. and SHELTON C.: Sugical rehabilitation of facial nerve paralysis. Otolaryngol. Clin. North Am., 30: 701-26, 1997.

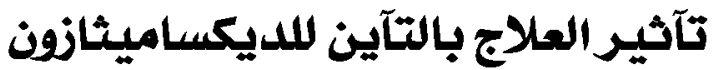 فى مرضى إلتهاب العصب السابن السابع الحاد العاد}

يهدف هذا البحث إلى دراسة تآثير العلاج بالتآين اللديكساميثانن في مرضى إلتهاب العصب السابع الحاد إشترك في هذا البحث ثلاثون مريضا (ما من الذكو وما من الإناث الذين يعانون من إلتهاب العصب السابع الحاد حيث تم تقسيمهم إلى مجموعتين متساويتين: • المجموعة الأقلى (المجموعة الضـابطة): تم علاجها بعلاج دوانى لمدة إسبوعين وصف بواسطة طبيب الآعصاب وعلاج مموه بإستخدام محلهل

• المجموعة الثانية (مجموعة الدراسة): تم علاجها بنفس برنامج المجموعة الضابطة مضافا إليها العلاج بالتآين اللديكساميثازنف.

حيث تم تقسيم المرضى قبل وبعد العلاج لتقييم درجة التصسن فى الحالات عن طريق درجات الإستجابة الكهربائية وجدل درجات يانانيهارا.

وقد آظهرت النتائج تصسن ذو دلالة إحصائية في كل من المجموعتين لصالح المجموعة الثانية.

وقد تبين لنا آفضلية إستخدام التآين اللديكساميثازون فى علاج إلتهاب العصب السـابع الحاد. 